\title{
Building Resilient Smart Cities for Sustainable Urban Tourism in Africa Post-COVID-19 Pandemic
}

\author{
Erisher Woyo $^{1(\bowtie)}(\mathbb{D})$ and Dandison $\mathrm{Ukpabi}^{2}$ (D) \\ 1 Tourism Research in Economic Environs and Society, North-West University, \\ Potchefstroom, South Africa \\ ${ }^{2}$ University of Jyväskylä, Jyväskylä, Finland \\ dandison.c.ukpabi@jyu.fi
}

\begin{abstract}
This paper contributes to the knowledge by examining the role of smart tourism technologies in destination resilience amidst the COVID-19 pandemic. Considering tourism in the COVID-19 crisis as an emerging stream of research, the study also explores how African cities deployed smart tourism technologies and how effective it has been in creating resilient and safe destinations. Data were collected through a semi-structured online interview from destination managers in Ghana, Kenya, and South Africa. The findings pose critical lessons for city destinations and how they need to transition into smartness to create safe spaces for travellers during and post-COVID-19. Our study makes novel contributions to literature and practice. Theoretically, our study fills the void identified in the relationship between STTs and COVID-19. Our study also offers practical recommendations that will accelerate African destination reset strategies.
\end{abstract}

Keywords: Smart cities $\cdot$ Smart technologies $\cdot$ Post-COVID-19 $\cdot$ Urban tourism $\cdot$ African cities

\section{Introduction}

As the world reels from the effect of COVID-19, different industries have structurally rebalanced their operations to remain competitive. Banks now mostly serve their customers via digital channels; the same is true for groceries and educational institutions [2]. The tourism industry is not an exception. Destinations are increasingly deploying virtual and augmented reality to connect with tourists [1, $21 \mathrm{pp}$. 1]. While these measures are essential for the short term, COVID-19 will be with us for a long time [28]. This requires destinations to strategically implement more digitally sustainable programmes to be resilient from the effects of the pandemic and remain competitive in the long term. The adoption of smart tourism technologies (STT) by tourist destinations has gained popularity in recent years [14, 24]. STTs imply various technologies embedded at destinations to enhance value-added to the people [4]. Studies have found that STTs are integral to tourists' satisfaction at destinations and their intention to revisit $[13 ; 14]$. STTs are also linked to urban resilience [9]. 
Resilience from COVID-19 is critical for the survival and competitiveness of destinations. However, literature is not clear on the role of STTs on resilience from the effect of COVID-19.

The United Nations World Tourism Organisation reported an increase of above 7\% and $2 \%$ on international tourist arrivals and receipts, respectively, in Africa in 2018 [27]. COVID-19 threatens the upward trajectory of this growth. Interestingly, there is a lack of empirical studies that have explored the nexus between STTs and resilience from COVID-19, especially from a developing country context. Using Africa as a case in point, the objective of this study is to examine the role of STTs in destination resilience amidst the COVID-19 pandemic. Specifically, this study explores (a) how different African destinations deploy STTs, (b) how effective has these STTs been in fostering destination resilience amidst COVID-19, and (c) what strategic implications STTs have for the future of African tourism.

Our study makes novel contributions to literature and practice. Theoretically, our study fills the void identified in the relationship between STTs and COVID-19. Furthermore, it builds the importance of smart technologies for African destinations generally deemed authoritative and unwilling to support national-level technologies. Our study also offers practical recommendations that will accelerate African destination reset strategies.

\section{Literature Review}

\subsection{Smart Cities and Smart Tourism Technologies/Destination}

The concept of smartness is a multidisciplinary term with several definitions depending on the context [4]. The smartness of a city implies interconnecting different information and communication technologies to enhance value for different stakeholders [14]. The proliferation of different ICTs has also created avenues for city administrators to creatively use them to enhance living and social services. In today's complex scenario, the role of the smart cities as leading actors to face Covid-19 and future pandemics cannot be overemphasised. Similarly, these ICT tools provide various value-enhancing experiences for tourists. Destination managers have used them to enhance tourists' experiences and increase destination competitiveness [4].

Smart tourism technologies (STTs) constitute general and specific ICT tools employed by destinations to enhance tourists' experiences and value $[12,14]$. While there are different variants of STTs, the most popular ones identified in literature includes social network sites, augmented reality, smartphones, beacons, the internet of things (IoT), cloud computing, sensors, mobile apps, Google maps, etc. [4, 13, 14]. The harmonious operation of these tools in creating, managing, and sustainably integrating them to enhance the touristic experience gives rise to the smart tourism ecosystem [11]. The literature identified such destinations as smart destinations [13].

Shafiee et al. [24] categorized smart tourism destinations under five components: stakeholders, structure, process, technology, and policies. Per stakeholders, these comprise the public and private sectors. Public sectors include national governments, while private sectors comprise active enterprises in smart tourism, information 
technology companies and other tourism organisations. For structure, they argue that it comprises strategic-communicative level, instrumental level, and applied level. Processes are value-creating process, decision-making process, digitization, and information exchange. The technology component comprises those as listed above. Lastly, policies deal with data access, privacy and security of customers' data, and personal data generated by smart devices.

On the other hand, smart tourism technologies possess four key attributes essential to their usability in each destination: informativeness, accessibility, interactivity, and personalization $[13,14]$. Informativeness implies the quality of the information from the STTs. Accessibility has to do with how tourists can easily access information from the destination via the STTs. On the other hand, interactivity implies how tourists can communicate effectively and obtain feedback via the STTs. Finally, personalization implies how tourists can obtain specific and relevant information suitable to them from the STTs.

Scholars have conducted empirical studies that examined the application of STTs on destinations and their effects on attractiveness and revisit intention. Huang et al. [13] found a positive association between the explorative use of STTs and travel experience satisfaction. Similarly, Jeong and Shin [14] found that the three key attributes of STTs (informativeness, interactivity and personalization) are positively associated with travellers' memorable experiences. In the same study, the memorable experience was also found to positively influence satisfaction and travellers' intention to visit.

\subsection{Resilient Smart Cities in Post-COVID-19}

Pandemics such as the current COVID-19 pose varying levels of challenges to cities and their inhabitants. Thus, the concept of resilience implies the "ability of a city to understand and prevent the disaster risks, mitigate those risks, and respond in such a way as to minimize loss of or damage to life, livelihoods, property, infrastructure, economic activity and the environment" [12 pp. 97]. Foreseeing risks and preparing adequately for them greatly enhances cities' ability to withstand those risks and equips them to bounce back immediately [23, 29].

Tourism is one of the most affected sectors due to the ongoing COVID-19 pandemic. Geographically, cities were significantly affected by the COVID-19 pandemic as they were hotspots for transmitting the virus [18]. However, as many destinations lift travel restrictions, sound recovery strategies are pertinent to remain competitive postCOVID-19. Scholarly evidence suggests that smart solutions are linked to urban resilience, such as community disaster resilience [9], emergency management [15], crime prevention [20] and disaster recovery [25, 30]. Thus, research notes that cities are becoming more resilient to crises due to their adoption of smart technologies, including IoT, artificial intelligence (AI) and big data [18]. For instance, the use of contact tracing apps could help check COVID-19 transmissions among tourists. The app could easily identify and alert relevant authorities where they are found $[22,26]$. Though STTs have strongly been linked to post-COVID-19 recovery strategies, research investigating their adoption in urban contexts have largely been done in cities in China and Western democracies [18], leaving African cities relatively understudied. 
This study foresees an uptick in adopting STTs by destinations as part of COVID19 recovery strategies. Tourists' perception of post-COVID-19 destination attractiveness would be hinged on the availability of accessible digital technologies. For instance, while social distancing and lowered mobility may continue post-COVID-19, augmented reality could be a critical technology to offer tourists deep, unique, contextspecific, and memorable experiences [21]. Even at the destination, the functionalities of STTs such as the internet, free Wi-Fi access points, big data and various social networking apps afford tourists up-to-date information on possible areas to avoid due to crowd and opportunities for information sharing.

\section{Methodology}

Smart tourism is an underexplored concept in Africa as a tourist destination. A qualitative methodology that followed an exploratory research design was employed in this study to examine the smart solutions implemented in East, West and Southern Africa cities as a response to building resilient cities post-COVID-19. Data were collected using a semi-structured interview guide. This instrument was chosen to allow participants to communicate how cities use smart solutions to create safe tourist spaces during the pandemic [7]. The instrument was designed based on a comprehensive review of literature on smart tourism and technology. We pretested the instrument before data collection, and unambiguous wording was revised accordingly. The interview schedule contained the following questions:

1. Do you think your destination or city has the networked infrastructure that enables informativeness and accessibility of tourism resources needed to support urban tourism development post -COVID-19?

2. What policies are available to support business-led urban development and creative industries to promote resilient urban tourism growth?

3. Your comment on the social inclusion of various urban stakeholders, including residents and social capital in urban tourism development for a safe and resilient post-COVID-19 city environment?

4. Are there any smart plans that your destination is currently pursuing to create resilient and safe tourist environments? They are hinged on what? Does your plan utilise any technologies? If yes, which ones?

5. Which technologies are you using as a destination to make the destination COVID19 safe and resilient?

6. Does the destination offer free internet, Wi-Fi access points, or other big data or open data technologies to enhance tourist experiences?

7. Do you think the official tourism website of the destination was created to be present throughout the tourist Lifecycle? Explain your answer?

8. Does your destination use QR codes? If yes, explain what they are used for?

9. As a destination, are you able to do data-driven marketing and base your decisions on data? Have you been able to collect data on the impact of smart solutions on the experiences of tourists?

10. Are tourists aware of any smart solutions in your destination? 
A combination of purposive and snowball sampling approaches was utilised in selecting participants. Destination managers recruited to participate in this study were from Kenya, Ghana, and South Africa. We used our professional networks to recruit participants using WhatsApp and emails. These platforms were used to confirm availability and consent to participate in the study. The messages sent to participants outlined the purpose of the study and its nature and explained why the participants' opinions were being sought. Furthermore, the participants were also informed of their right to participate and withdraw at any time during the research. No financial incentives were offered for participation. Destination managers were eventually invited to refer the researchers to other managers in their respective countries and cities. Data were collected until saturation, and the anonymity of the participants was guaranteed.

Participants were interviewed between June and July 2021 using MS Teams and Zoom facilities, and each interview lasted approximately $30 \mathrm{~min}$. Interviews were conducted in English. Creswell [6] recommended conducting between 5 to 25 interviews to reach data saturation. In this study, data saturation was reached after 9 interviews. All the interviews were done synchronously, and the details are summarised in Table 1. Interviews were conducted, transcribed, and analysed using thematic analysis. Data analysis started with full data transcription, data familiarisation, codes identification, searching, reviewing, defining themes, and generating results. Coding was performed manually through repeated reading of and making notes on interview transcripts.

Table 1. Participants' profile

\begin{tabular}{l|l|l}
\hline Participant ID & Gender & Location \\
\hline DM1 & Male & Nakuru, Kenya \\
\hline DM2 & Female & Accra, Ghana \\
\hline DM3 & Male & Tshwane, South Africa \\
\hline DM4 & Female & Accra, Ghana \\
\hline DM5 & Male & Nairobi, Kenya \\
\hline DM6 & Male & Nairobi, Kenya \\
\hline DM7 & Female & Accra, Ghana \\
\hline DM8 & Male & Johannesburg, South Africa \\
\hline DM9 & Male & Johannesburg, South Africa \\
\hline
\end{tabular}

\section{Findings}

Based on the analysis of the interviews, it was possible to examine and categorize smart solutions being used by the destination to create safe and resilient cities for a postpandemic era. The findings of the study are organised based on the objectives, namely (1) how different African cities deployed STTs during the COVID-19 pandemic, (2) how effective has these STTs been fostering safe and resilient cities amidst COVID19 and (3) the strategic implications STTs in creating safe and resilient tourism cities in Africa. 


\subsection{Deployment of STTs in African Cities During COVID-19}

To achieve greater resilience during COVID-19 for the travel industry, cities need to implement a range of smart technologies [10]. Such technological interventions are critical given that currently, anything that involves touch is frowned up. A destination manager from Nakuru City in Kenya argued that "digital cities are important, as they give tourists a perception of safety". This view is consistent with past research that advocated for developing digitalized cities as a fundamental concept of smart tourism [3, 19]. Further data analysis shows more smart technologies deployment during COVID in Kenya than in South Africa and Ghana. This could be explained by the commitment of the Kenyan government, as summed up by this quote:

"There is a greater government involvement in enabling the utilisation of technologies. For instance, there was a creation of the Data Protection Commission of Kenya, to help with data breaches".

The South African government has made similar efforts that saw the Presidential Commission on Fourth Industrial Revolution being established to drive the smartness concept. Table 2 provides a range of smart technologies deployed to create safe spaces for tourism in Ghanaian, Kenyan, and South African cities during COVID-19. Key among the interventions was promoting mobile payments, reducing data bundles, using drones, and contact tracing apps. The aspect of mobile money payments was already in existence in Kenya but was magnified during the pandemic. These findings are consistent with earlier studies [16,31] that argued that using such technologies is critical in decreasing contact among tourists and contagion.

Table 2. Interventions and STTs deployed during COVID-19 in African cities.

\begin{tabular}{l|l|l}
\hline Intervention(s) & Location & Objective \\
\hline $\begin{array}{l}\text { Portals; Interactive } \\
\text { dashboards, toll-free lines, } \\
\text { and WhatsApp channels (in } \\
\text { multiple languages) }\end{array}$ & $\begin{array}{l}\text { Ghanaian, Kenyan, and } \\
\text { South African cities }\end{array}$ & $\begin{array}{l}\text { To disseminate reliable } \\
\text { information on the pandemic } \\
\text { as well as enable citizens to } \\
\text { report suspected cases }\end{array}$ \\
\hline $\begin{array}{l}\text { Digital platforms } \\
\text { Cashless payments }\end{array}$ & $\begin{array}{l}\text { Ghanaian, Kenyan and } \\
\text { South African cities } \\
\text { Remote learning; working } \\
\text { from home; service } \\
\text { providers such as health, } \\
\text { banking, and entertainment }\end{array}$ \\
\hline Doubling internet speeds & $\begin{array}{l}\text { More pronounced in } \\
\text { Kenyan cities; Ghana, and } \\
\text { South Africa }\end{array}$ & $\begin{array}{l}\text { To reduce contagion and } \\
\text { transactional fees were } \\
\text { waived }\end{array}$ \\
\hline Kenya (Google Loon) & $\begin{array}{l}\text { To enhance universal 4G } \\
\text { coverage and connectivity in } \\
\text { the country for people } \\
\text { working from home. Speeds } \\
\text { were doubled at no extra } \\
\text { costs }\end{array}$ \\
\hline
\end{tabular}


Table 2. (continued)

\begin{tabular}{l|l|l}
\hline Intervention(s) & Location & Objective \\
\hline Contact tracing apps & $\begin{array}{l}\text { Kenyan cities of Nairobi } \\
\text { and Kisumu (Msafari); } \\
\text { Ghana (GH COVID-19 } \\
\text { Tracker App), and South } \\
\text { Africa }\end{array}$ & $\begin{array}{l}\text { To track passengers on } \\
\text { public transport }\end{array}$ \\
\hline Drones & $\begin{array}{l}\text { Ghana, Kenya, and South } \\
\text { Africa }\end{array}$ & $\begin{array}{l}\text { To ferry medicines, blood, } \\
\text { vaccines and share } \\
\text { information about the } \\
\text { pandemic }\end{array}$ \\
\hline $\begin{array}{l}\text { Promotional of work from } \\
\text { home data bundles }\end{array}$ & Kenya & $\begin{array}{l}\text { Campaign to educate the } \\
\text { public on the pandemic }\end{array}$ \\
\hline QR codes & Kenya and South Africa & $\begin{array}{l}\text { For online ordering, virtual } \\
\text { queues in restaurants, } \\
\text { hospitals and reducing } \\
\text { restaurant visits }\end{array}$ \\
\hline
\end{tabular}

Before COVID-19, there was a huge convergence of disruptive effects in the form of new technologies. As a result, this resulted in the proliferation and consolidation of smart cities. However, with consumer concerns for more sustainable, resilient, and safer spaces, technologies in the African cities of Accra, Nairobi, Nakuru, Cape Town, and Johannesburg are at the heart of city development and the tourism sector. There was a consensus among participants from all the cities that COVI-19 has increased the need for a smart technological solution to safer tourism. The participants noted an increased usage of STTs in cities, tourism establishments, hotels, and restaurants to manage the spread of COVID-19. Most of the cited technologies used are aimed at decreasing tourist contacts.

\subsection{STTs' Effectiveness in Fostering Safe and Resilient Cities Amidst COVID-19}

The study sought to establish how effective STTs were in creating safe and resilient tourism cities during the COVID-19 pandemic. Participants from Kenya and South Africa pointed out coordinated efforts between the government and other stakeholders in creating safer and resilient cities during the pandemic. This was evidenced by the creation of the Data Protection Commission of Kenya. Though there was a huge drive for technological solutions in South Africa pre-COVID-19, through the formation of the Presidential Commission on the Fourth Industrial Revolution (PC4IR), destination managers from South Africa argued that efforts to create smart tourism in the city of Tshwane, Johannesburg and Cape Town appears to be slower. Past research has long identified these aspects as critical in developing smart cities for enhanced tourism competitiveness [8]. 
"I think due to the effort of the government of Kenya, smart technologies have been effective in making our cities safe and resilient."

"In South Africa, the pace before COVID-19 was amazing. However, more could be done to create safe and resilient urban spaces".

"The government of Kenya has a full-fledged ICT, Innovation and Youth Affairs ministry driving smart innovations to reduce transmission during COVID-19".

"Data Protection Commission of Kenya is responsible for dealing with complaints about the data breach, and this is a critical step in creating safe and resilient spaces for tourists in Kenya."

Based on the narratives received from participants in Kenya, it appears that STTs were more effective in fostering safe and resilient cities amidst the COVID-19 pandemic. This could be attributed to government policy and innovative digital culture. Regarding Ghana, the participants noted that the digital innovation aspect is rather silent, and therefore, the notion that STTs are thus not driving more from the government. However, one destination manager from Ghana noted that "more recently, the ministry of health has been distributing COVID-19 vaccines to remote areas as a means of speeding up its vaccination campaign, and this is a right step in ensuring that cities in Ghana are safe for tourism purposes".

There are currently no public policy plans in Ghana to direct the implementation of smart technological solutions, as is the case in Kenya and South Africa. The use of drones in delivering vaccines is a welcome solution. This could be more meaningful if the government put policies to promote the usage of smart technologies.

\subsection{Implications of STTs in a Post-pandemic City Environment}

One of the key attributes of STTs is to ensure that tourism products and services are accessible. Due to COVID-19, participants from all three countries noted that the demand for STTs was high, given its implications on tourist safety. [21] argue that using STTs during and post-pandemic must also ensure aspects of uniqueness, accessibility, personalisation, context-specific, memorable experiences among travellers. The data analysis shows that Kenyan tourism is currently implementing several smart technologies to build decision support systems of the destination to deepen travellers' experiences.

A destination manager from Kenya mentioned that "building an information hub is necessary though current efforts around that are currently fragmented". Most participants in Kenya and South Africa argued for the need to develop regulated and coordinated information hubs. This was argued as critical in ensuring that information about COVID-19, COVID-19 guidelines, visas, and attractions is widely accessible for tourists during and post-pandemic. Participants mentioned that using STTs such as drones, GIS, and QR codes is crucial in providing thematic maps to help cities with smart elements of accessibility and informativeness. One destination manager from South Africa added that "using smart technologies is critical in helping tourists during COVID-19 understand the destination comprehensively". This view is consistent with past literature that argues that such provision of smart technologies is imperative for enhancing visitors' experiences [21]. 


\begin{abstract}
"Technologies are crucial in enhancing the promotion of Kenya tourism to domestic and international travellers during and post-pandemic."

"We are currently implementing smart solutions that help tourists identify and find the best tourism spots here in Kenya. QR codes are widely used in Kenya for this aspect".

"South Africa, at the beginning of the pandemic, has been using drones and geospatial technologies. This should continue in the future to provide timely information about COVID-19".

"Mapping of existing and potential tourism facilities, services, infrastructure, resources, and attractions using smart technologies is important in displaying the well-known tourism products and opening the underutilized regions."
\end{abstract}

Most of the technologies used in Kenya and South Africa are aimed at digital mapping as a strategic response. The study also found that South Africa, just like Kenya, has been using GIS and location technologies to provide real-time visualizations, identify hotspots, and update current progress on its national dashboards. A study on smart cities in South Korea showed that through technologies, firms, citizens, and the government could flatten the curve during the COVID-19 pandemic without closing their borders [17]. In this case, the proactive exchange of information allowed tourists to form a shared comprehension of the context while complying with the rules and security measures adopted to increase trust in the institution's ability to manage the crisis.

This is critical in enhancing the informativeness attribute for smart tourism and the creation of safe tourism cities. Tourist maps have also been known to play vital roles in identifying and locating tourist attractions and have essential roles in the effective and efficient management of tourism resources. The creation of smart tourism cities, thus, depends on the availability of information that comes with spatial representation. This enables the analysis of the virus patterns and helps tourists to make informed decisions.

"In Kenya, we recently launched a digital mapping of tourism resources using drones, and it is a strategy that aims to enhance smart conservation".

"All wildlife in Kenya is set to be counted using drones in the next six months. Geographical Information System (GIS)".

"The use of GIS and location technologies during the pandemic has been very helpful for South Africa in creating safe spaces by helping travellers identify hotspots and be aware of current progress".

Though mapping will be important in promoting safe and resilient tourism cities in Africa post-COVID-19, the role of the government in implementing smart solutions is relatively limited in the empirical context of Ghana. However, these findings show that smart tourism among African cities will be integral in the post-pandemic era, given their ability to provide tourists with an enhanced public health environment.

\title{
5 Conclusion
}

The study examined the smart technologies adopted by African cities in Ghana, Kenya, and South Africa to create safe, and resilient smart tourism cities. The findings show that cities in Kenya, Ghana and South Africa differ significantly in adopting smart technologies to create safe cities. In Kenya and South Africa, the findings show that the government actively coordinated and controlled the narrative of smart technologies based on initiatives such as the Data Protection Commission of Kenya and the 
Presidential Commission on the Fourth Industrial Revolution in South Africa. However, cities in Ghana seem to lack coordination efforts with the national government to create safe spaces using smart technologies. Overall, the usage of smart technologies differed significantly.

Unlike research that focuses on the negative impacts caused by the pandemic, this paper focuses on evaluating actions and strategies based on the adoption of smart technologies in the respective countries to face the pandemic. The study highlights those smart technological responses are useful in dealing with an ongoing pandemic, even in a continent that often disregards such technologies as a means of wielding political power. Thus, instead of suppressing the consumption of smart technologies, African governments may gain full control over a situation by adopting a techno-driven approach when faced with a pandemic. Furthermore, the contribution of this study lies in bringing a perspective of developing countries in the African region. However, there is an overall concern that governments in Africa, generally known to be authoritative, may take advantage of the Covid-19 to reinforce technological visioning on citizens beyond controlling the pandemic.

African cities must fully benefit from these technologies to ensure that stakeholders increase smart governance and equitable data distribution [5]. Furthermore, based on Kenya's findings, there is a need for continued government participation, especially in creating an enabling environment crucial for creating sustainable smart cities.

\section{References}

1. Akhtar $\mathrm{N}$ et al (2021) Post-COVID 19 tourism: will digital tourism replace mass tourism? Sustainability 13(10):5352

2. Baig A, Hall B, Jenkins P, Lamarre E, McCarthy B (2020) The COVID-19 recovery will be digital: a plan for the first 90 days. McKinsey Digital 14

3. Bassano C, Barile S, Piciocchi P, Spohrer JC, Iandolo F, Fisk R (2019) Storytelling about places: tourism marketing in the digital age. Cities 87:10-20

4. Boes K, Buhalis D, Inversini A (2015) Conceptualising smart tourism destination dimensions. In: Tussyadiah I, Inversini A (eds) Information and communication technologies in tourism 2015. Springer, Cham, pp 391-403. https://doi.org/10.1007/978-3-31914343-9_29

5. Choi J, Lee S, Jamal T (2021) Smart Korea: governance for smart justice during a global pandemic. J Sustain Tour 29(2-3):541-550

6. Creswell JW (1998) Qualitative inquiry and research design: choosing among five traditions. SAGE Publications, Thousand Oaks, CA, Thousand Oaks, CA

7. Creswell JW, Creswell JD (2018) Research design: qualitative, quantitative, and mixed methods approaches, 5th edn. SAGE Publications, Los Angeles, Los Angeles

8. Dredge D, Phi G, Mahaderavan R, Neehan E, Popescu ES (2018) Digitalisation in Tourism: in-depth analysis of challenges and opportunities. Low value procedure GRO-SME-17-C091-A for Executive Agency for Small and Medium-sized Enterprises (EASME) virtual tourism observatory. Aalborg University Copenhagen (2018)

9. Dufty N (2012) Using social media to build community disaster resilience. Australian J Emerg Manag 27(1):40-45 
10. Gretzel U, Koo C (2021) Smart tourism cities: a duality of place where technology supports the convergence of touristic and residential experiences. Asia Pac J Tour Res 26(4):352-364

11. Gretzel U, Werthner H, Koo C, Lamsfus C (2015) Conceptual foundations for understanding smart tourism ecosystems. Comput Hum Behav 50:558-563

12. Hernantes J, Maraña P, Gimenez R, Sarriegi JM, Labaka L (2019) Towards resilient cities: a maturity model for operationalizing resilience. Cities 84:96-103

13. Huang CD, Goo J, Nam K, Yoo CW (2017) Smart tourism technologies in travel planning: the role of exploration and exploitation. Inf Manag 54(6):757-770

14. Jeong M, Shin HH (2020) Tourists' experiences with smart tourism technology at smart destinations and their behavior intentions. J Travel Res 59(8):1464-1477

15. Ji Z, Anwen Q (2010) The application of internet of things (IOT) in emergency management system in China. In: 2010 IEEE international conference on technologies for homeland security (HST), IEEE, pp 139-142

16. Jiang Y, Wen J (2020) Effects of COVID-19 on hotel marketing and management: a perspective article. Int J Contemp Hosp Manag 32(8):2563-2573

17. Jo W, Lee J, Park J, Kim Y (2020) Online information exchange and anxiety spread in the early stage of the novel coronavirus (COVID-19) outbreak in South Korea: structural topic model and network analysis. J Med Int Res 22(6):e19455

18. Kummitha RKR (2020) Smart technologies for fighting pandemics: the techno-and humandriven approaches in controlling the virus transmission. Govern Inf Q 37(3):101481

19. Kunzmann KR (2020) Smart cities after COVID-19: ten narratives. disP - Plann Rev 56 (2):20-31

20. Lee JS, Park S, Jung S (2016) Effect of crime prevention through environmental design (CPTED) measures on active living and fear of crime. Sustainability 8(9):872

21. Mohanty P, Hassan A, Ekis E (2020) Augmented reality for relaunching tourism postCOVID-19: socially distant, virtually connected. Worldwide Hosp Tour Themes 12(6):753760

22. Munzert S, Selb P, Gohdes A, Stoetzer LF, Lowe W (2021) Tracking and promoting the usage of a COVID-19 contact tracing app. Nat Hum Behav 5(2):247-255

23. Poku-Boansi M, Cobbinah PB (2018) Are we planning for resilient cities in Ghana? An analysis of policy and planners' perspectives. Cities 72:252-260

24. Shafiee S, Ghatari AR, Hasanzadeh A, Jahanyan S (2021) Smart tourism destinations: a systematic review. Tour Rev 76(3):505-528

25. Suri $\mathrm{N}$ et al (2018) Exploiting smart city IoT for disaster recovery operations. In: 2018 IEEE 4th world forum on Internet of Things (WF-IoT), IEEE, pp 458-463

26. Ukpabi D, Olaleye S, Karjaluoto H (2021) Factors influencing tourists' intention to use covid-19 contact tracing app. In: Wörndl W, Koo C, Stienmetz JL (eds) Information and Communication Technologies in Tourism 2021. Springer, Cham, pp 504-516. https://doi. org/10.1007/978-3-030-65785-7_48

27. UNWTO (2019) International tourism highlights. World Tourism Organisation. Madrid

28. World Health Organisation (WHO) (2020) WHO Director-General's opening remarks at the media briefing on COVID-19. https://www.who.int/director-general/speeches/detail/whodirector-general-s-opening-remarks-at-the-media-briefing-on-covid-19-22-april-2020.

Accessed 19 Aug 2021 
29. Woyo E (2021) The sustainability of using domestic tourism as a post-COVID-19 recovery strategy in a distressed destination. In: Wörndl W, Koo C, Stienmetz JL (eds) Information and Communication Technologies in Tourism 2021. Springer, Cham, pp 476-489. https:// doi.org/10.1007/978-3-030-65785-7_46

30. Yao F, Wang Y (2020) Towards resilient and smart cities: a real-time urban analytical and geo-visual system for social media streaming data. Sustain Cities Soc 63:102448

31. Zeng Z, Chen PJ, Lew AA (2020) From high-touch to high-tech: COVID-19 drives robotics adoption. Tour Geogr 22(3):724-734

Open Access This chapter is licensed under the terms of the Creative Commons Attribution 4.0 International License (http://creativecommons.org/licenses/by/4.0/), which permits use, sharing, adaptation, distribution and reproduction in any medium or format, as long as you give appropriate credit to the original author(s) and the source, provide a link to the Creative Commons license and indicate if changes were made.

The images or other third party material in this chapter are included in the chapter's Creative Commons license, unless indicated otherwise in a credit line to the material. If material is not included in the chapter's Creative Commons license and your intended use is not permitted by statutory regulation or exceeds the permitted use, you will need to obtain permission directly from the copyright holder.

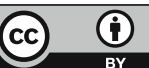

